\title{
Preface to the Italian Edition* (1962/1966)
}

The German text of Dialectic of Enlightenment is a fragment. Begun as early as 1942, during the Second World War, it was supposed to form the introduction to the theory of society and history we had sketched during the period of National Socialist rule. It is self-evident that, with regard to terminology and the scope of the questions investigated, the book is shaped by the social conditions in which it was written.

In keeping with its theme, our book demonstrates tendencies which turn cultural progress into its opposite. We attempted to do this on the basis of social phenomena of the I930s and I940s in America. However, to construct a systematic theory which would do justice to the present economic and political circumstances is a task which, for objective and subjective reasons, we are unable to perform today. We are therefore happy that the fragment is appearing in a series devoted predominantly to philosophical questions.

Frankfurt am Main, March 1966

M.H. and T.W.A. 